\title{
Growth of carbon nanofibers from methane on a hydroxyapatite-supported nickel catalyst
}

\author{
Ewa Miniach ${ }^{1}$, Agata Śliwak ${ }^{1}$, Adam Moyseowicz ${ }^{1}$, and Grażyna Gryglewicz ${ }^{1, \star}$ \\ ${ }^{1}$ Department of Polymer and Carbonaceous Materials, Faculty of Chemistry, Wrocław University of Technology, Gdańska 7/9, \\ 50-344 Wrocław, Poland
}

Received: 25 October 2015

Accepted: 16 February 2016

Published online:

25 February 2016

(C) The Author(s) 2016. This article is published with open access at Springerlink.com

\begin{abstract}
Carbon nanofibers (CNFs) were grown using catalytic chemical vapor deposition (CCVD) with methane as the carbon source and a hydroxyapatite-supported nickel catalyst (Ni/HAp). The catalyst, which contained approximately $14 \mathrm{wt} \% \mathrm{Ni}$, was prepared using the incipient wetness method with an aqueous nickel nitrate solution. Temperature-programmed reduction and X-ray diffraction were used to characterize the active phase of Ni/HAp. Three variables were evaluated to optimize the CNF growth process, including the temperature and the time of catalyst reduction as well as the reaction time, at $650{ }^{\circ} \mathrm{C}$. Regardless of the applied CCVD process conditions, herringbone bamboo-like CNFs were grown during methane decomposition over Ni/HAp, which was confirmed using transmission electron microscopy. A high CNF yield of nearly $10 \mathrm{~g}_{\mathrm{CNF}} \mathrm{g}_{\mathrm{cat}}^{-1}$ was achieved at $650{ }^{\circ} \mathrm{C}$ after a reaction time of $3 \mathrm{~h}$ when the catalyst was subjected to a reduction at the same temperature for $2 \mathrm{~h}$ under a hydrogen flow prior to synthesis. As the reduction temperature increased from 450 to $650{ }^{\circ} \mathrm{C}$, both the yield and diameters of the CNFs increased. The beneficial effects of including hydrogen in the reaction mixture on the catalytic performance of $\mathrm{Ni}$ / HAp and the purity of the grown CNFs were demonstrated.
\end{abstract}

\section{Introduction}

Carbon nanofibers (CNFs), which include carbon nanotubes (CNTs), have been synthesized since the 1960s. However, the most significant discovery regarding CNTs was in 1991 when Iijima reported that highly graphitized carbon, which was formed from the arc discharge of graphite electrodes, contained several coaxial tubes and a hollow core [1].
Since this study was reported, the synthesis and application of CNFs/CNTs have attracted increasing interest due to their variety of extraordinary structures, which provide unique mechanical and electromagnetic properties, chemical inertness, high conductivity, surface properties, and ease of structure control [2]. Catalytic chemical vapor deposition (CCVD) using hydrocarbons is the most extensively used method to produce CNFs due to its high efficiency and selectivity at low costs. Many variables

Address correspondence to E-mail: grazyna.gryglewicz@pwr.edu.pl 
affect CNF growth, such as the catalyst composition, reducibility of the catalyst, nature of the metal/support interaction, particle size of the active metal, synthesis temperature, carbon source, and composition of the reaction gas mixture [3-6]. The search for an efficient catalytic system that can provide good stability and dispersion of a catalytic active metal as well as high yield of well-defined carbon nanostructures remains the subject of much research $[7,8]$.

Methane decomposition over transition metals such as $\mathrm{Ni}, \mathrm{Fe}$ or $\mathrm{Co}$, is a promising approach for CNF synthesis due to the abundance and low cost of natural gas. Among the catalysts, $\mathrm{Ni}$ is characterized by exhibiting the highest catalytic activity in the production of CNFs $[9,10]$. In most studies, $\mathrm{Ni}$ was deposited on widely used supports, such as $\mathrm{Al}_{2} \mathrm{O}_{3}$, $\mathrm{SiO}_{2}, \mathrm{TiO}_{2}, \mathrm{MgO}$ [11, 12], and zeolites [13] in addition to activated carbon [14, 15] and carbon nanofibers/nanotubes [16, 17]. Herein, we report the use of hydroxyapatite (HAp) as a support for a $\mathrm{Ni}$ catalyst to produce CNFs using methane decomposition. Only a few studies on the use of HAp as a catalyst support to produce CNF/HAp composites using a mixture of methane and nitrogen have been reported for potential applications in the dental and medical fields [18-20]. CNF-containing HAp-based composites are candidates for use in implants due to their enhanced mechanical properties [21-23]. The chemical inertness of HAp is an important property for a material that will be used as a catalyst support. HAp does not exhibit any catalytic activity during the high-temperature treatment [20] or create spinels that would lead to a reduction in the catalyst reducibility, which is often observed for alumina-supported nickel catalysts [24, 25]. Therefore, HAp appears to be a good support for $\mathrm{Ni}$ catalysts for the synthesis of CNF using CCVD.

In this study, selected variables of the CCVD process were studied to obtain CNFs with high yield and purity using a $\mathrm{Ni} / \mathrm{HAp}$ catalyst and methane as the carbon source. We focused on the catalyst reduction conditions in the CCVD process because they are rarely reported in the literature. Our results demonstrate that the optimization of the temperature and time of catalyst reduction is crucial for high-yield $\mathrm{CNF}$ synthesis. For optimal reduction conditions, the kinetics of CNF growth were studied to evaluate the susceptibility of $\mathrm{Ni} / \mathrm{HAp}$ to deactivation.

\section{Experimental}

\section{Catalyst preparation}

Hydroxyapatite (HAp) with a purity grade of $97 \%$ (Sigma-Aldrich, particle size $<200 \mathrm{~nm}$ ) was used as the support. The HAp-supported $\mathrm{Ni}$ catalyst was prepared using the incipient wetness method with an aqueous solution of $\mathrm{Ni}\left(\mathrm{NO}_{3}\right) \cdot 6 \mathrm{H}_{2} \mathrm{O}$ (ACROS Organics, $99 \%$ ). The amount of $\mathrm{Ni}$ precursor was adjusted to achieve a $\mathrm{Ni}$ weight loading of $14 \mathrm{wt} \%$ in the catalyst. The sample was further dried at $110{ }^{\circ} \mathrm{C}$ for $2 \mathrm{~h}$ and subsequently calcined in a nitrogen atmosphere at $350{ }^{\circ} \mathrm{C}$ for $4 \mathrm{~h}$. The Ni content in the catalyst was determined to be $13.4 \mathrm{wt} \%$ using atomic absorption spectroscopy (AAS). The prepared catalyst is referred to as $\mathrm{Ni}$ /HAp.

\section{Synthesis of CNFs}

CNFs were synthesized using CCVD with methane as the carbon precursor. First, $200 \mathrm{mg}$ of the Ni/HAp catalyst was loaded in a quartz boat and placed in a quartz tube in the central heat zone of a conventional horizontal furnace. Prior to CNF growth, the catalyst was reduced under hydrogen flowing at a rate of $150 \mathrm{ml} \mathrm{min}{ }^{-1}$ at various temperatures $\left(450-650{ }^{\circ} \mathrm{C}\right)$ and times (10-120 min). After the reduction, a mixture of $\mathrm{CH}_{4}$ and $\mathrm{H}_{2}\left(1: 1, \mathrm{v} / \mathrm{v}, 150 \mathrm{ml} \mathrm{min}^{-1}\right)$ was passed through the quartz tube at $650{ }^{\circ} \mathrm{C}$. The reaction time was varied from 3 to $180 \mathrm{~min}$. The resulting CNFs were subsequently cooled to ambient temperature in a nitrogen atmosphere. Both the catalyst reduction and the $\mathrm{CNF}$ synthesis were performed at atmospheric pressure. The purity grades of $\mathrm{CH}_{4}, \mathrm{H}_{2}$, and $\mathrm{N}_{2}$ were 99.995, 99.999, and $99.999 \%$, respectively.

The yield $(Y)$ of CNFs was calculated based on the catalyst weight increase during the reaction using the following equation:

$Y=\frac{m_{\mathrm{t}}-m_{\mathrm{cat}}}{m_{\mathrm{cat}}}$,

where $Y$ is the yield of CNF expressed in $g_{C N F}$ per $g_{\text {cat }}$ $\left[g_{\mathrm{CNF}} \mathrm{g}_{\text {cat }}^{-1}\right], m_{\mathrm{t}}$ is the total weight of the catalyst and the deposited carbon at the end of the reaction, and $m_{\text {cat }}$ is the initial mass of the catalyst. Additionally, the yield $\left(Y_{\mathrm{Ni}}\right)$ was expressed per gram of metal $\left(\mathrm{g}_{\mathrm{CNF}} \mathrm{g}_{\mathrm{Ni}}^{-1}\right)$ according to the following equation: 
$\Upsilon_{\mathrm{Ni}}=\frac{m_{\mathrm{t}}-m_{\mathrm{cat}}}{0.134 \cdot m_{\mathrm{cat}}}$

The difference in the CNF yield for two separate runs, which were performed using the same experimental conditions, was not higher than $7 \%$ of the average yield. The as-received CNFs were treated with $5 \% \mathrm{HCl}$ for $2 \mathrm{~h}$ at room temperature in a sonication bath to remove the nickel and hydroxyapatite. Subsequently, the samples were washed with distilled water, filtered, and dried at $110{ }^{\circ} \mathrm{C}$ for $2 \mathrm{~h}$.

\section{Catalyst characterization}

The nickel content in the $\mathrm{Ni} / \mathrm{HAp}$ catalyst was determined by AAS using a SOLAAR S4 spectrometer. Temperature-programmed reduction (TPR) was performed on a ChemBET 3000 analyzer (Quantachrome) using a reducing mixture of $\mathrm{H}_{2}(5 \%$ $\mathrm{v} / \mathrm{v})-\operatorname{Ar}\left(100 \mathrm{ml} \mathrm{min}^{-1}\right)$. The catalyst sample was heated at a rate of $20^{\circ} \mathrm{C} \mathrm{min}{ }^{-1}$ from ambient temperature to $980{ }^{\circ} \mathrm{C}$. The hydrogen consumption was determined using $\mathrm{CuO}$ as a standard for the TPR analysis. X-ray diffraction (XRD) analysis was performed on an Ultima IV Rigaku diffractometer using CuK $\alpha$ radiation $(\lambda=1.54056 \AA)$. The average sizes of the $\mathrm{NiO}$ and $\mathrm{Ni}$ crystallites were calculated using Scherrer's equation.

\section{CNF characterization}

The morphologies of the as-grown and purified CNFs, HAp, and as-prepared $\mathrm{Ni} / \mathrm{HAp}$ catalyst were studied using scanning electron microscopy (SEM) on an EVO LS15 Zeiss microscope. The arrangement of graphene layers in the CNFs was determined by transmission electron microscopy (TEM) using a FEI Tecnai $G^{2} 20$ X-TWIN microscope, which was operated at an acceleration voltage of $200 \mathrm{kV}$. The sample was prepared by ultrasonic dispersion in ethanol, and a few drops of the suspension were placed onto a copper microgrid covered with a perforated carbon film. The average CNF diameter was determined based on the measurement of 50 nanofibers for each sample. Thermogravimetric analysis (TGA) was performed on the purified CNFs using a TGA/DSC1 Mettler Toledo (thermobalance).

\section{Results and discussion}

\section{Catalyst characterization}

Figure 1 shows the $X$-ray diffraction patterns of the as-prepared (a) and reduced Ni/HAp (b) catalysts. For the as-prepared Ni/HAp catalyst, we observed diffraction peaks arising from different planes of the $\mathrm{NiO}$ phase (i.e., $2 \theta=37.2^{\circ}(111), 43.2^{\circ}$ (200), $62.9^{\circ}$ (220), $75.5^{\circ}$ (311), and $79.5^{\circ}$ (222)) (Fig. 1a) [ICSD No:01-1239]. The diffraction peaks at $2 \theta=25.9^{\circ}(002)$, $29.0^{\circ}(210), 31.8^{\circ}(211), 32.2^{\circ}(112), 32.9^{\circ}(300), 34.0^{\circ}$ (202), $39.8^{\circ}(310), 46.7^{\circ}(222), 49.5^{\circ}$ (213), $50.5^{\circ}$ (321), and $53.1^{\circ}$ (004) were due to the crystalline $\mathrm{Ca}_{5}\left(\mathrm{PO}_{4}\right)_{3}(\mathrm{OH})$ phase. The average size of the $\mathrm{NiO}$ crystallites, which was determined using XRD, was $22 \mathrm{~nm}$ for the fresh $\mathrm{Ni} / \mathrm{HAp}$ catalyst. After catalyst reduction at $650{ }^{\circ} \mathrm{C}$ for $2 \mathrm{~h}$, the XRD pattern (Fig. 1b) showed diffraction peaks arising from metallic $\mathrm{Ni}$ (i.e., $2 \theta=44.4^{\circ}(111), 51.8^{\circ}$ (200), and $76.4^{\circ}$ (220)) [ICSD No:04-0850]. The Ni crystallite size was bigger than that of $\mathrm{NiO}$ ( 34 vs. $22 \mathrm{~nm}$ ), suggesting sintering and aggregation of the nickel phase during the heat treatment in a hydrogen atmosphere. The strong influence of the metal particle size on the CNF yield has been previously reported [7, 26, 27]. Excessively small metal particles will not form CNFs because the quantity of metal is not sufficient to enable $\mathrm{CNF}$ formation according to the proposed mechanism of CNF growth during CCVD. In contrast, excessively large metal particles are inactive because the carbon diffusion through these particles is hindered [28]. Chen et al. [7] reported the relationship between the $\mathrm{NiO}$ particle size of a hydrotalcite-supported catalyst and the yield of CNFs produced from methane decomposition. The most suitable $\mathrm{NiO}$ particle sizes, which constitute the catalytic centers for $\mathrm{CNF}$ growth after the hydrogen treatment, were determined to be approximately $34 \mathrm{~nm}$. Moreover, based on XRD analysis, the average $\mathrm{NiO}$ crystal size of the as-prepared catalyst was comparable to the $\mathrm{Ni}$ crystal size of the reduced catalyst, which was determined by chemisorption [7]. Therefore, the synthesized Ni/ HAp catalyst with an average $\mathrm{Ni}$ crystallite size of $34 \mathrm{~nm}$ appears to be a promising catalytic system for CNF growth. Some studies [26, 27] have reported that $\mathrm{Ni}$ particles with sizes of 10-60 nm are characteristic of highly active catalysts for the production of CNFs via methane decomposition. 


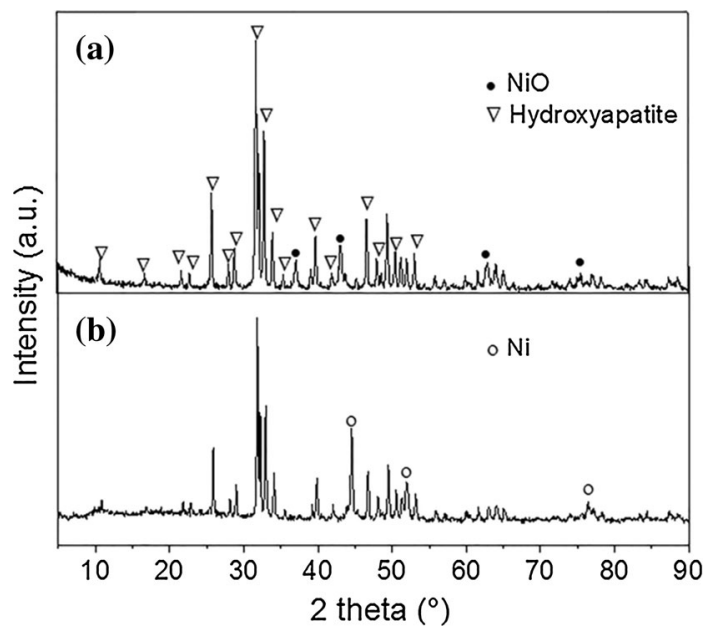

Figure 1 XRD pattern of the fresh $\mathrm{Ni} / \mathrm{HAp}$ catalyst (a) and reduced $\mathrm{Ni} / \mathrm{HAp}$ catalyst (b).

The morphology of the as-prepared Ni/HAp catalyst was very similar to that of the support (Fig. S1). The HAp powder consists of agglomerated spherical nanoparticles, and their sizes are preserved in the $\mathrm{Ni} / \mathrm{HAp}$ catalyst. SEM-EDX investigation of the reduced $\mathrm{Ni} / \mathrm{HAp}$ catalyst revealed that nickel was homogeneously distributed on the surface of the support particles (Fig. S2).

The reducibility of the Ni/HAp catalyst, which was characterized by the TPR profile, is shown in Fig. 2. Only one wide peak with a maximum at $470{ }^{\circ} \mathrm{C}$ was observed due to the reduction of $\mathrm{NiO}$ to metallic Ni. A small shoulder on the curve at approximately $380{ }^{\circ} \mathrm{C}$ may correspond to the reduction of very fine $\mathrm{NiO}$ particles. The reduction of $\mathrm{NiO}$ began at $200{ }^{\circ} \mathrm{C}$ and ended at $670{ }^{\circ} \mathrm{C}$. The hydrogen consumption determined by TPR was $2.08 \mathrm{mmol} \mathrm{g}^{-1}$.

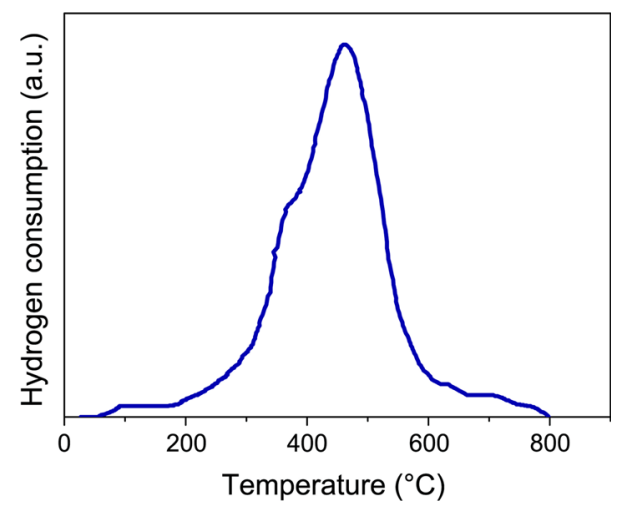

Figure 2 TPR profile of the Ni/HAp catalyst.

\section{Effect of the reduction temperature}

Based on the TPR results, a temperature range of 450 to $650{ }^{\circ} \mathrm{C}$ was selected to determine the effect of the $\mathrm{Ni} / \mathrm{HAp}$ reduction temperature on the yield, morphology, and structure of the grown CNFs. The CNFs were synthesized at $650{ }^{\circ} \mathrm{C}$ using methane diluted with hydrogen in a ratio of $1: 1(\mathrm{v} / \mathrm{v})$. The reduction time was $2 \mathrm{~h}$. The CNF yields, which depend on the reduction temperature of the $\mathrm{Ni} / \mathrm{HAp}$ catalyst, are listed in Table 1. As the reduction temperature increased from 450 to $650{ }^{\circ} \mathrm{C}$, the $\mathrm{CNF}$ yield increased from 3.9 to $5.9 \mathrm{~g}_{\mathrm{CNF}} \mathrm{g}_{\text {cat }}^{-1}$, which may be due to the increasing number of $\mathrm{Ni}$ active sites on the catalyst surface. The latter result is supported by the TPR profile of Ni/HAp (Fig. 2), which indicates that approximately half of the $\mathrm{NiO}$ was reduced to the metallic form at $450{ }^{\circ} \mathrm{C}$. Pronounced CNF growth was observed up to $600{ }^{\circ} \mathrm{C}$, but further CNF growth was only slightly higher at $650{ }^{\circ} \mathrm{C}$. As expected, this growth was followed by an increase in the amount of $\mathrm{Ni}$, which contributed to the CNF growth and yielded $42.5 \mathrm{~g}_{\mathrm{CNF}} \mathrm{g}_{\mathrm{Ni}}^{-1}$ at $650{ }^{\circ} \mathrm{C}$ compared to $27.6 \mathrm{~g}_{\mathrm{CNF}}$ $\mathrm{g}_{\mathrm{Ni}}^{-1}$ at $450{ }^{\circ} \mathrm{C}$. An enhancement in $\mathrm{CNF}$ growth from methane over a $\mathrm{Ni}-\mathrm{Cu}-\mathrm{MgO}$ catalyst with an increase in the reduction temperature from 600 to $1000{ }^{\circ} \mathrm{C}$ has also been reported by Wang et al. [29].

Figure 3 shows the TEM images of the as-grown CNFs, which were synthesized over the $\mathrm{Ni} / \mathrm{HAp}$ catalyst and reduced at different temperatures. Regardless of the reduction temperature, the graphene layers were stacked at an angle to the fiber axis, which indicates the presence of their herringbone structural type. The herringbone bamboo-like $\mathrm{CNFs}$ were primarily grown on the surface of the $\mathrm{Ni}$ / HAp catalyst. CNFs with a herringbone-type graphene layer arrangement exhibit open edges on their outer surface, which result in high chemical activity and may be beneficial in medical and other applications. The presence of $\mathrm{Ni}$ particles at the ends of the

Table 1 Effect of the Ni/HAp reduction temperature on $\mathrm{CNF}$ growth

\begin{tabular}{lll}
\hline Temperature $\left({ }^{\circ} \mathrm{C}\right)$ & \multicolumn{2}{l}{ Reaction yield } \\
\cline { 2 - 3 } & $\left(\mathrm{g}_{\mathrm{CNF}} \mathrm{g}_{\mathrm{cat}}^{-1}\right)$ & $\left(\mathrm{g}_{\mathrm{CNF}} \mathrm{g}_{\mathrm{Ni}}^{-1}\right)$ \\
\hline 450 & 3.9 & 27.6 \\
550 & 4.2 & 30.3 \\
600 & 5.8 & 41.6 \\
650 & 5.9 & 42.5 \\
\hline
\end{tabular}


nanofibers suggests a tip-growth mechanism due to weak catalyst-support interactions [8]. The herringbone type of CNFs is a typical structure that forms during CCVD when using methane over a Ni catalyst [30]. The diameters of the grown CNFs were determined by TEM. As shown in Fig. 4, the CNF diameters increased as the reduction temperature increased. At $550{ }^{\circ} \mathrm{C}, \mathrm{CNFs}$ with a diameter of 25-45 nm were grown with a predominant contribution of narrower nanofibers. At $600{ }^{\circ} \mathrm{C}$, a wide distribution of CNF diameters in the range of 25-55 nm was observed. CNFs with a diameter of 36-55 nm were obtained when the Ni/HAp catalyst was reduced at $650{ }^{\circ} \mathrm{C}$. The shift in the CNF diameter to larger values as the reduction temperature increases was due to an increase in the Ni crystallite size. CNFs with larger diameters were also grown by increasing the reaction temperature $[16,31]$.

An increase in the reduction temperature can lead to the migration of nickel particles on the support surface and formation of larger agglomerates, which results in larger CNF diameters. However, the catalyst, operating conditions, and reactant gas composition affect the CNF diameters [32]. In our study, the most suitable temperature for $\mathrm{Ni} / \mathrm{HAp}$ reduction was determined to be $650{ }^{\circ} \mathrm{C}$, which results in maximum reduction of the $\mathrm{NiO}$ phase.

\section{Effect of the reduction time}

In general, a higher amount of $\mathrm{NiO}$ reduced to a metallic form corresponds to a higher CNF yield. The extent of catalyst reduction depends on both the temperature and reduction time. The effect of the reduction time on $\mathrm{CNF}$ growth was investigated at $650{ }^{\circ} \mathrm{C}$, where the maximum conversion of $\mathrm{NiO}$ to $\mathrm{Ni}$ was observed. After catalyst reduction, the CNFs were synthesized at the same temperature for $1 \mathrm{~h}$ using a mixture of methane and hydrogen at a ratio of $1: 1(\mathrm{v} / \mathrm{v})$. Figure 5 shows the effect of the reduction time on the CNF growth over Ni/HAp. An increase in the catalyst reduction times led to a higher $\mathrm{CNF}$ yield, which is due to the increased amounts of reduced metallic nickel. A maximum $\mathrm{CNF}$ weight gain $\left(5.9 \mathrm{~g}_{\mathrm{CNF}} \mathrm{g}_{\text {cat }}^{-1}\right)$ was obtained at $2 \mathrm{~h}$ of reduction. A sharp increase in CNF growth was observed for up to $30 \mathrm{~min}$ of reduction, and then, the growth rate subsequently decreased. The plateau in the plot of the yield as a function of the reduction time indicates that $2 \mathrm{~h}$ is an optimal time for activation of all of the catalytic $\mathrm{Ni}$ centers on the HAp surface. Longer reduction times most likely promote the formation of large agglomerates of $\mathrm{Ni}$, which are unable to catalyze the decomposition of methane.

Figure 6 shows the SEM images of the obtained $\mathrm{CNFs}$ at different $\mathrm{Ni} / \mathrm{HAp}$ reduction times. After 10 min of reduction, the CNFs were heterogeneously dispersed on the catalyst surface and characterized by a broad size distribution, which ranged from short to several micrometers in length (Fig. 6a). An increase in the reduction time to 60 min produced a strong entangled network of nanofibers that were more than a dozen micrometers in length (Fig. 6b). A dense network of entangled nanofibers was observed when $\mathrm{Ni} / \mathrm{HAp}$ was reduced at $650{ }^{\circ} \mathrm{C}$ for $2 \mathrm{~h}$. The obtained results indicate that a reduction time of $2 \mathrm{~h}$ is optimal for CNF production over the $\mathrm{Ni} / \mathrm{HAp}$ catalyst.
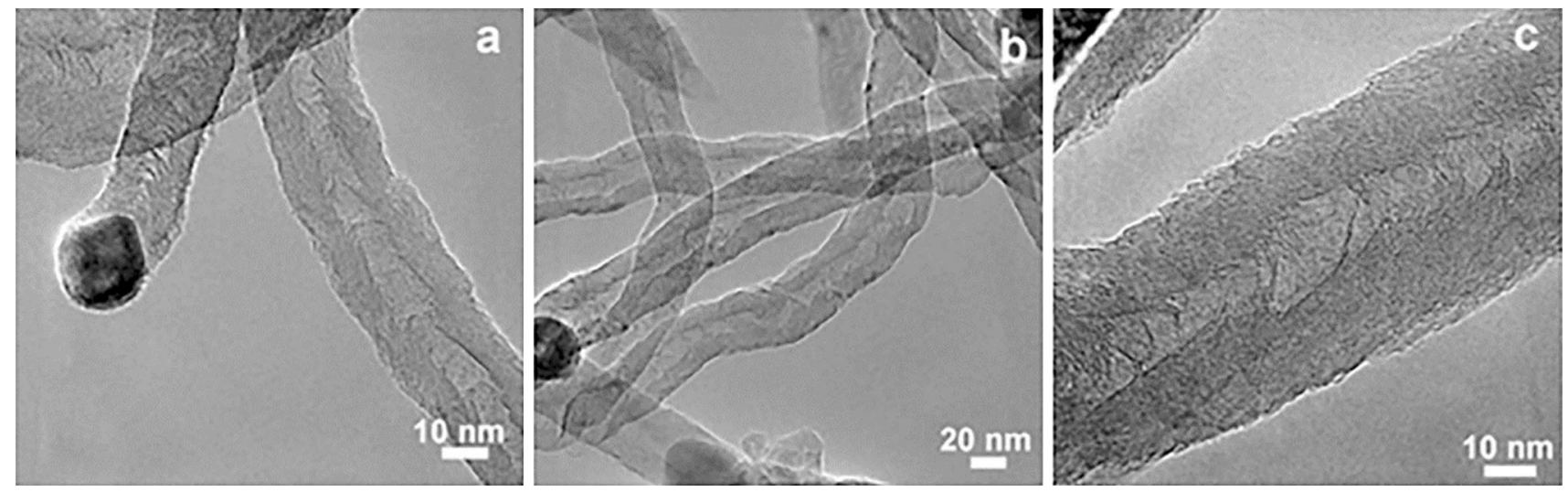

Figure 3 TEM images of CNFs synthesized with a catalyst reduction at $550{ }^{\circ} \mathrm{C}(\mathrm{a}), 600{ }^{\circ} \mathrm{C}(\mathrm{b})$, and $650{ }^{\circ} \mathrm{C}(\mathbf{c})$. 


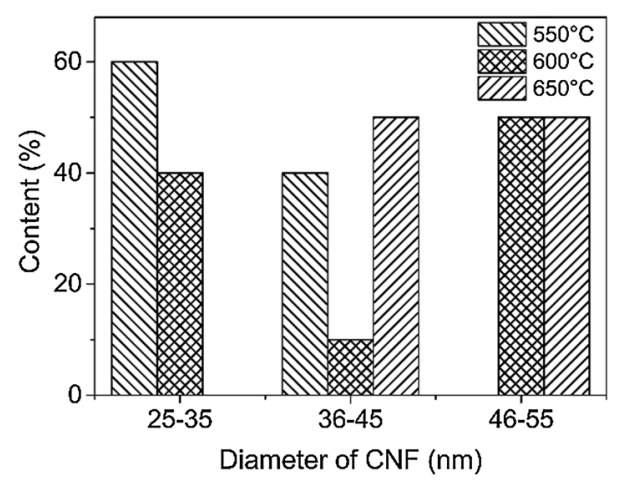

Figure 4 Diameter distribution of CNFs as a function of the reduction temperature of $\mathrm{Ni} / \mathrm{HAp}$.

\section{Kinetics of CNF growth}

The temperature of CCVD is crucial to the growth of CNFs $[13,17]$. For a given catalyst, the temperature must be higher than the decomposition temperature of the carbon precursor on the catalyst surface. An increase in the synthesis temperature results in an enhanced CNF yield but only to a certain extent. Excessive temperatures promote the uncontrolled deposition of carbon as well as the migration of metallic catalyst nanoparticles across the surface, resulting in the formation of large nanoparticles that do not promote $\mathrm{CNF}$ growth. An increase in reaction temperature up to $600-650{ }^{\circ} \mathrm{C}$ increases methane conversion to filamentous carbon and hydrogen over Ni catalysts [33], which is consistent with results for $\mathrm{Ni}$ catalysts that exhibit the highest activity toward methane decomposition at $650{ }^{\circ} \mathrm{C}$ [34]. In our study, the kinetic study of the CNF growth over $\mathrm{Ni} / \mathrm{HAp}$ was performed at $650{ }^{\circ} \mathrm{C}$ using a mixture of $\mathrm{CH}_{4}$ and $\mathrm{H}_{2}$. Prior to CNF growth, the Ni/HAp catalyst was reduced with hydrogen under the previously determined optimal conditions (i.e., at $650{ }^{\circ} \mathrm{C}$ for $2 \mathrm{~h}$ ). Figure 7 shows the $\mathrm{CNF}$ yield as a function of the synthesis time.

An increase in the CNF productivity from 0.15 to $9.92 \mathrm{~g}_{\mathrm{CNF}} \mathrm{g}_{\text {cat }}^{-1}$ was observed when the reaction time was increased from 3 to $180 \mathrm{~min}$. During the first few minutes of the process, only a small portion of $\mathrm{Ni}$ contributed to the CNF growth $\left(1.12 \mathrm{~g}_{\mathrm{CNF}} \mathrm{g}_{\mathrm{Ni}}^{-1}\right)$. After $180 \mathrm{~min}$, a large amount of $\mathrm{Ni}$ was involved in CNF growth $\left(74.03 \mathrm{~g}_{\mathrm{CNF}} \mathrm{g}_{\mathrm{Ni}}^{-1}\right)$. The highest rate of $\mathrm{CNF}$ growth was observed during the first hour of synthesis. At longer reaction times, the growth of the CNFs slightly decreased. The high yield of CNFs

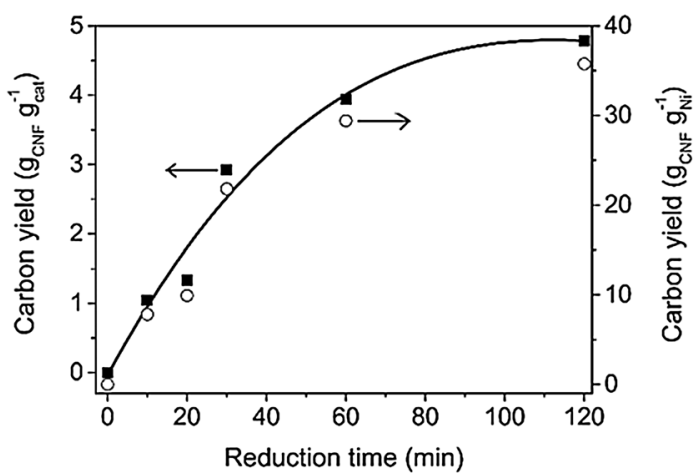

Figure 5 Relationship between the CNF yield and the reduction time of $\mathrm{Ni} / \mathrm{HAp}$ at $650{ }^{\circ} \mathrm{C}$.

after $3 \mathrm{~h}$ of synthesis (nearly $10 \mathrm{~g}_{\mathrm{CNF}} \mathrm{g}_{\mathrm{cat}}^{-1}$ ) was due to the large amount of the nickel active phase, which results from the hydrogen in the reaction gas mixture preventing deposition of amorphous carbon on the catalyst surface. The presence of hydrogen in the reaction mixture plays a crucial role in the formation of CNFs due to the decomposition of hydrocarbons [31, 35]. Hydrogen can either accelerate or suppress the formation of carbon [36], which affects the yield and morphology of the resulting CNFs as well as catalyst deactivation. This effect can be interpreted in multiple ways. Hydrogen, which is present in the feed stream along with methane, may be responsible for the decomposition of nickel carbides to form catalytically active metal particles [37] or remove the graphite overlayer that encapsulates the catalyst active surface [38]. In our study, hydrogen undoubtedly facilitates $\mathrm{CNF}$ growth by maintaining the catalytic activity of $\mathrm{Ni}$, which leads to a high $\mathrm{CNF}$ yield. A continuous weight gain of CNFs with synthesis time may be related to hydrogen activation of new catalytic centers that were not activated during the catalyst reduction step. The two processes can occur simultaneously (i.e., the reduction of $\mathrm{NiO}$ nanoparticles to create new active sites for $\mathrm{CNF}$ growth and the decomposition of methane on previously activated $\mathrm{Ni}$ centers, which both lead to an increase in the length of nanofibers). This result is supported by SEM investigations of the CNFs obtained using different synthesis times (Fig. 8).

After a reaction time of $3 \mathrm{~min}$, the catalyst surface was not entirely coated with $\mathrm{CNFs}$, which were several micrometers in length (Fig. 8a). Much longer and entangled CNFs appeared after a longer synthesis time (Fig. 8b). The increasing number of nanofibers 
Figure 6 SEM images of the CNFs obtained after $10 \mathrm{~min}$ (a) and $60 \mathrm{~min}$ (b) of $\mathrm{Ni} / \mathrm{HAp}$ reduction.
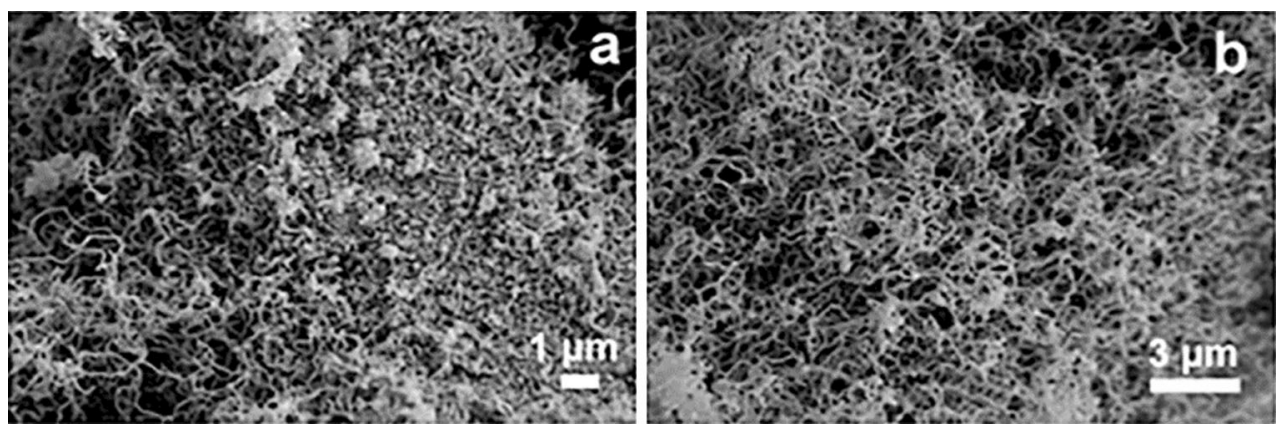

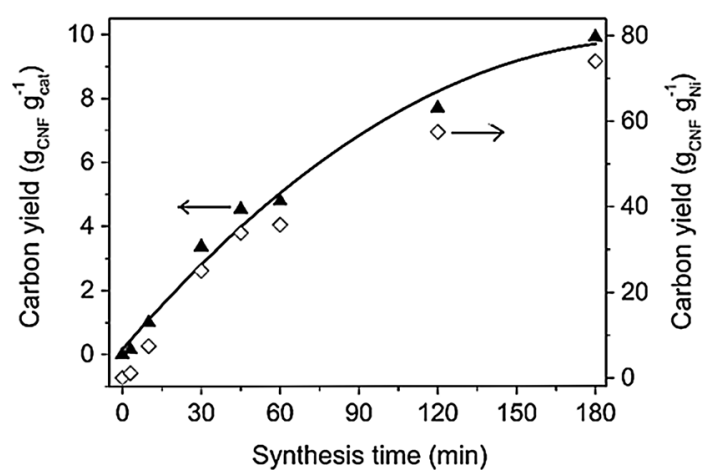

Figure $7 \mathrm{CNF}$ growth as a function of the synthesis time over the $\mathrm{Ni} / \mathrm{HAp}$ catalyst at $650^{\circ} \mathrm{C}$.

on the support surface suggests the creation of new active sites during CCVD, which is supported by the higher $\mathrm{CNF}$ yield expressed as $\mathrm{g}_{\mathrm{CNF}} \mathrm{g}_{\mathrm{Ni}}^{-1}$. After a reaction time of $180 \mathrm{~min}$, the entire surface was coated with a dense layer of strongly entangled nanofibers that were $10 \mu \mathrm{m}$ in length (Fig. 8c), providing a yield of approximately $10 \mathrm{~g}_{\mathrm{CNF}} \mathrm{g}_{\text {cat }}^{-1}$. It is important to note that by adjusting the reaction time, $\mathrm{CNF} / \mathrm{HAp}$ composites with adjustable CNFs contents and lengths can be tailored for specific requirements.

The beneficial effect of hydrogen on the CNF growth over $\mathrm{Ni} / \mathrm{HAp}$ using methane as a carbon precursor can also be demonstrated by comparing the obtained CNF yields with those reported by Ashok et al. [20]. The Ni/HAp catalyst with $15 \mathrm{wt} \%$ of $\mathrm{Ni}$ after $4 \mathrm{~h}$ of synthesis at $650{ }^{\circ} \mathrm{C}$ in a methane stream (without hydrogen) produced $0.76 \mathrm{~g}_{\mathrm{CNF}} \mathrm{g}_{\text {cat }}^{-1}$ of CNFs. In our study, a mixture of methane and hydrogen resulted in a CNF yield that was several times greater to as high as $9.92 \mathrm{~g}_{\mathrm{CNF}} \mathrm{g}_{\text {cat }}^{-1}$. Few studies of Ni catalysts based on different supports with high performance in hydrocarbon decomposition to produce $\mathrm{CNFs}$ have been reported (e.g., $\mathrm{Ni} / \mathrm{Al}_{2} \mathrm{O}_{3}$ with $90 \mathrm{wt} \%$ of metal loading) [39]. This catalyst enabled a $\mathrm{CNF}$ yield of $20 \mathrm{~g}_{\mathrm{CNF}} \mathrm{g}_{\text {cat }}^{-1}$ after $2 \mathrm{~h}$ of reaction. However, the difficulties associated with the thermal instability of $\mathrm{Al}_{2} \mathrm{O}_{3}$ and its low mechanical strength have been reported by Boukha et al. [25]. Moreover, alumina can create spinels with nickel, which prevents the formation of nickel growth centers [25]. Based on these negative features, alumina can be replaced by other promising $\mathrm{Ni}$ catalyst supports, such as the studied hydroxyapatite, which has excellent mechanical properties and does not react with nickel.

It is interesting to note that although notably high yields of CNFs were obtained, amorphous carbon was not formed during the CCVD process, which
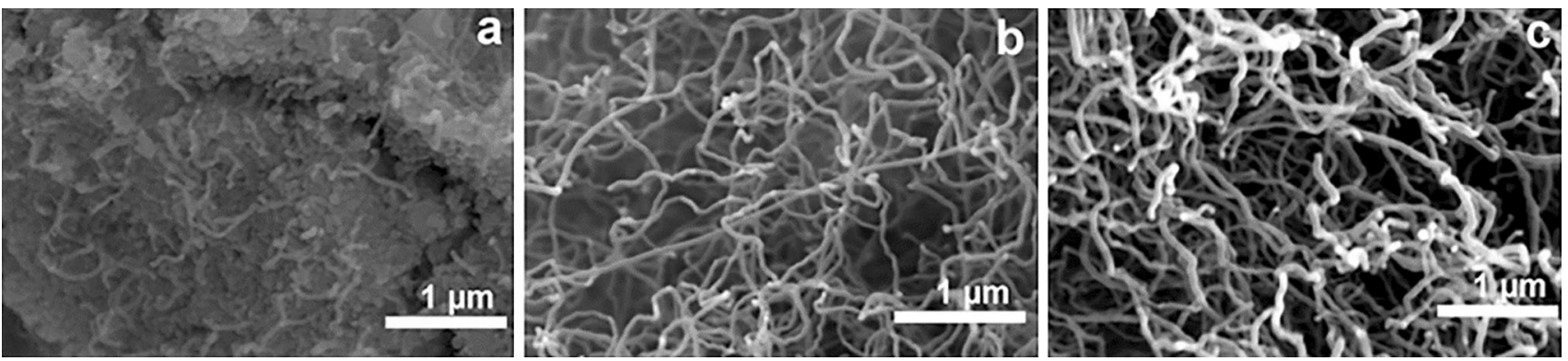

Figure 8 SEM images of CNFs synthesized at $650{ }^{\circ} \mathrm{C}$ for $3 \mathrm{~min}(\mathbf{a}), 60 \mathrm{~min}(\mathbf{b})$, and $180 \mathrm{~min}$ (c). 


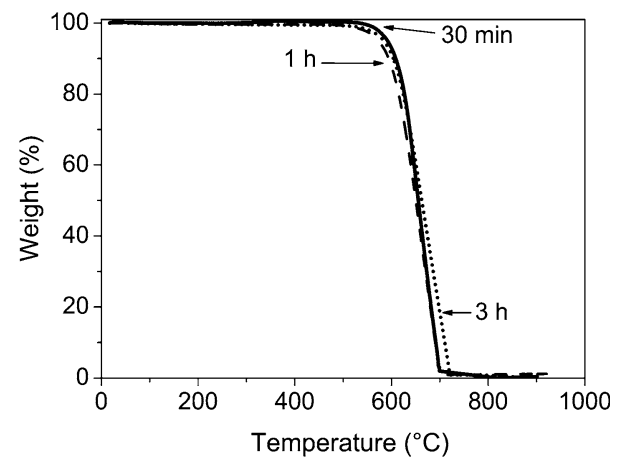

Figure 9 TGA curves of CNFs synthesized with different reaction times.

was confirmed by SEM analysis. This result suggests that the presence of hydrogen in the reaction mixture efficiently prevents the deposition of undesirable carbon. The TGA analysis revealed a similar oxidation behavior of the resulting CNFs regardless of the synthesis time (Fig. 9).

The weight loss, which may be due to the noncrystalline structure of carbonaceous materials, such as amorphous carbon, occurred between 300 and $400{ }^{\circ} \mathrm{C}$. In this temperature range, no oxidation was observed even for the CNFs synthesized for $3 \mathrm{~h}$. This result demonstrates that a highly ordered graphitic structure without amorphous carbon is characteristic of CNFs that are synthesized over $\mathrm{Ni} / \mathrm{HAp}$ using a $\mathrm{CH}_{4}$ and $\mathrm{H}_{2}$ mixture.

\section{Conclusions}

This study demonstrates that the use of hydroxyapatite as a support for a nickel catalyst results in the production of herringbone bamboo-like CNFs in a high yield with no amorphous carbon by CCVD using a mixture of methane and hydrogen as the reactant gas. At a reaction temperature of $650{ }^{\circ} \mathrm{C}$, the growth of $\mathrm{CNFs}$ and their diameter distribution strongly depended on the catalyst reduction temperature. An increase in the reduction temperature of $\mathrm{Ni} / \mathrm{HAp}$ from 450 to $650{ }^{\circ} \mathrm{C}$ increased the $\mathrm{CNF}$ growth due to the larger amount of reduced metallic nickel. Moreover, reduction at higher temperatures produced CNFs with larger diameters due to agglomeration of nickel particles during the high-temperature treatment. This result suggests that the diameter distribution of the grown CNFs can be tailored by adjusting the reduction temperature of the catalyst. A notably high CNF yield up to approximately $10 \mathrm{~g}_{\mathrm{CNF}} \mathrm{g}_{\text {cat }}^{-1}$, was obtained at $650{ }^{\circ} \mathrm{C}$ with a reaction time of $3 \mathrm{~h}$ when $\mathrm{Ni} / \mathrm{HAp}$ was reduced at $650{ }^{\circ} \mathrm{C}$ for $2 \mathrm{~h}$. At this temperature, all of the reducible $\mathrm{NiO}$ in the $\mathrm{Ni} / \mathrm{HAp}$ catalyst was converted to the metallic form, which was confirmed by TPR. Due to the inertness of hydroxyapatite and the presence of hydrogen in the reaction mixture, the Ni/HAp catalyst was resistant to deactivation and maintained its catalytic activity during CNF growth over long CCVD processing times. Due to the graphitic edges that were exposed on the outer surface of the herringbone CNFs, this structure has a high potential for modification, which may create new applications for CNF/HAp composites.

\section{Acknowledgements}

This work was financed by a statutory activity subsidy from the Polish Ministry of Science and Higher Education for the Faculty of Chemistry of Wrocław University of Technology. The project was supported by Wrocław Centre of Biotechnology, under The Leading National Research Centre (KNOW) programme for years 2014-2018.

\section{Compliance with ethical standards}

Conflict of interest The authors declare that they have no conflict of interest.

Open Access This article is distributed under the terms of the Creative Commons Attribution 4.0 International License (http://creativecommons.org/licen ses/by/4.0/), which permits unrestricted use, distribution, and reproduction in any medium, provided you give appropriate credit to the original author(s) and the source, provide a link to the Creative Commons license, and indicate if changes were made.

Electronic supplementary material: The online version of this article (doi:10.1007/s10853-016-98391) contains supplementary material, which is available to authorized users.

\section{References}

[1] Iijima S (1991) Helical microtubules of graphitic carbon. Nature 354:56-58 
[2] Feng L, Xie N, Zhong J (2014) Carbon nanofibers and their composites: a review of synthesizing, properties and applications. Materials 7:3919-3945

[3] Zhou JH, Sui ZJ, Li P, Chen D, Dai YC, Yuan WK (2006) Structural characterization of carbon nanofibers formed from different carbon-containing gases. Carbon 44:3255-3266

[4] Tessonier JP, Rosenthal D, Hansen TW, Hess Ch, Schuster ME, Blume R, Girsdies F, Pfander N, Timpe O, Su DS, Schlogl R (2009) Analysis of the structure and chemical properties of some commercial carbon nanostructures. Carbon 47:1779-1798

[5] Moyseowicz A, Śliwak A, Gryglewicz G (2016) Influence of structural and textural parameters of carbon nanofibers on their capacitive behavior. J Mater Sci 51:3431-3439. doi:10. 1007/s10853-015-9660-2

[6] Yu L, Qin Y, Sui L, Zhang Q, Cui Z (2008) Two opposite growth modes of carbon nanofibers prepared by catalytic decomposition of acetylene at low temperature. J Mater Sci 43:883-886. doi:10.1007/s10853-007-2191-8

[7] Chen D, Christensen KO, Ochoa-Fernandez E, Yu Z, Totdal B, Latorre N, Monzon A, Holmen A (2005) Synthesis of carbon nanofibers: effects of Ni crystal size during methane decomposition. J Catal 229:82-96

[8] Vander Wal RL, Ticich TM, Curtis VE (2001) Substratesupport interactions in metal catalyzed carbon nanofiber growth. Carbon 39:2277-2289

[9] Yamada Y, Hosono Y, Murakoshi N, Higashi N, Ichi-oka H, Miyake Tet al (2006) Carbon nanofiber formation on iron group metal loaded on $\mathrm{SiO}_{2}$. Diam Relat Mater 15(4-8):1080-1084

[10] Romero A, Garrido A, Nieto-Marquez A, Sanchez P, de Lucas A, Valverde JL (2008) Synthesis and structural characteristics of highly graphitized carbon nanofibers produced from the catalytic decomposition of ethylene: influence of the active metal $(\mathrm{Co}, \mathrm{Ni}, \mathrm{Fe})$ and the zeolite type support. Microporous Mesoporous Mater 110(2-3):318-329

[11] Takenaka S, Shigeta Y, Tanabe E, Otsuka K (2003) Methane decomposition into hydrogen and carbon nanofibers over supported Pd-Ni catalysts. J Catal 220:468-477

[12] Li Y, Li D, Wang G (2011) Methane decomposition to $\mathrm{CO}_{\mathrm{x}}$ - free hydrogen and nano-carbon material on group 8-10 base metal catalysts: a review. Catal Today 162:1-48

[13] De Lucas A, Garrido A, Sanchez P, Romero A, Valverde JL (2005) Growth of carbon nanofibers from Ni/Y zeolite based catalysts: effects of $\mathrm{Ni}$ introduction method, reaction temperature, and reaction gas composition. Ind Eng Chem Res 44:8225-8236

[14] Rinaldi A, Abdullah N, Ali M, Furche A, Bee Abd Hamid S, Sheng Su S, Schlogl R (2009) Controlling the yield and structure of carbon nanofibers grown on a nickel/activated carbon catalyst. Carbon 47:3023-3033
[15] Gryglewicz G, Śliwak A, Beguin F (2013) Carbon nanofibers grafted on activated carbon as an electrode in highpower supercapacitors. ChemSusChem 6:1516-1522

[16] Romero A, Garrido A, Nieto-Marquez A, Raquel de la Oa A, de Lucas A, Valverde JL (2007) The influence of operating conditions on the growth of carbon nanofibers on carbon nanofiber-supported nickel catalyst. Appl Catal A 319:246-258

[17] Zhao Y, Li Ch, Yao K, Liang J (2007) Preparation of carbon nanofibers over carbon nanotube-nickel catalyst in propylene decomposition. J Mater Sci 42:4240-4244. doi:10.1007/ s10853-006-0676-5

[18] Li H, Zhao N, Liu Y, Liang C, Shi C, Du X, Li J (2008) Fabrication and properties of carbon nanotubes reinforced Fe/hydroxyapatite composites by in situ chemical vapor deposition. Compos A 39(7):1128-1132

[19] Li H, Wang L, Liang C, Wang Z, Zhao W (2010) Dispersion of carbon nanotubes in hydroxyapatite powder by in situ chemical vapor deposition. Mater Sci Eng B 166(1):19-23

[20] Ashok J, Naveen Kumar S, Subrahmanyam M, Venugopal A (2008) Pure $\mathrm{H}_{2}$ production by decomposition of methane over Ni supported on hydroxyapatite catalyst. Catal Lett 121:283-290

[21] Kaya C (2008) Electrophoretic deposition of carbon nanotube-reinforced hydroxyapatite bioactive layers on Ti-6Al$4 \mathrm{~V}$ alloys for biomedical applications. Ceram Int 34:1843-1847

[22] Mukherjee S, Kundu B, Sen S, Chanda A (2014) Improved properties of hydroxyapatite-carbon nanotube biocomposite: mechanical, in vitro bioactivity and biological studies. Ceram Int 40:5635-5643

[23] Prodana M, Duta M, Ionita D, Bojin D, Stan MS, Dinischiotu A, Demetrescu I (2015) A new complex ceramic coating with carbon nanotubes, hydroxyapatite and $\mathrm{TiO}_{2}$ nanotubes on $\mathrm{Ti}$ surface for biomedical applications. Ceram Int 41:6318-6325

[24] Piao L, Li Y, Chen J, Chang L, Lin JYS (2002) Methane decomposition to carbon nanotubes and hydrogen on an alumina supported nickel aerogel catalyst. Catal Today 74(1-2):145-155

[25] Boukha Z, Jimenez-Gonzalez C, de Rivas B, Gonzalez-Velasco JR, Gutierrez-Ortiz JI, Lopez-Fonseca R (2014) Synthesis, characterization and performance evaluation of spinel-derived $\mathrm{Al}_{2} \mathrm{O}_{3}$ catalysts for various methane reforming reactions. Appl Catal B 158-159:190-201

[26] Ermakova MA, Ermakov DY, Kuvshinov GG, Plasova LM (1999) New nickel catalysts for the formation of filamentous carbon in the reaction of methane decomposition. J Catal $187: 77-84$

[27] Ermakova MA, Ermakov DY, Kuvshinov GG (2000) Effective catalysts for direct cracking of methane to produce 
hydrogen and filamentous carbon part I. Nickel catalysts. Appl Catal A 201:61-70

[28] Chinthaginjala JK, Seshan K, Lefferts L (2007) Preparation and application of carbon-nanofiber based microstructured materials as catalyst supports. Ind Eng Chem Res 46(12):3968-3978

[29] Wang H, Terry R, Baker K (2004) Decomposition of methane over a $\mathrm{Ni}-\mathrm{Cu}-\mathrm{MgO}$ catalyst to produce hydrogen and carbon nanofibers. J Phys Chem B 108:20273-20277

[30] Takenaka S, Kobayashi S, Ogihara H, Otsuka K (2003) Ni/ $\mathrm{SiO}_{2}$ catalyst effective for methane decomposition into hydrogen and carbon nanofiber. J Catal 217:79-87

[31] Singh C, Shaffer MSP, Windle AH (2003) Production of controlled architectures of aligned carbon nanotubes by an injection chemical vapour deposition method. Carbon 41(2):359-368

[32] Jong KPD, Geus JW (2000) Carbon nanofibers: catalytic synthesis and applications. Cat Rev Sci Eng 42:481-510

[33] Zhang W, Ge Q, Xu H (2011) Influences of reaction conditions on methane decomposition over non-supported $\mathrm{Ni}$ catalyst. J Nat Gas Chem 20:339-344
[34] Zhang W, Ge Q, Xu H (2010) Influences of precipitate rinsing solvents on $\mathrm{Ni}$ catalyst for methane decomposition to $\mathrm{CO}_{\mathrm{x}}$-free hydrogen. J Phys Chem A 114:38183823

[35] Vieira R, Ledoux MJ, Pham-Huu C (2004) Synthesis and characterization of carbon nanofibers with macroscopic shaping formed by catalytic decomposition of $\mathrm{C}_{2} \mathrm{H}_{2} / \mathrm{H}_{2}$ over nickel catalyst. Appl Catal A 274:1-8

[36] Ci L, Wei J, Wei B, Liang J, Xu C, Wu D (2001) Carbon nanofibers and single-walled carbon nanotubes prepared by the floating catalyst method. Carbon 39:329-335

[37] Yang KL, Yang RT (1986) The accelerating and retarding effects of hydrogen on carbon deposition on metal surfaces. Carbon 24:687-693

[38] Kim MS, Rodriguez NM, Baker RTK (1991) The interaction of hydrocarbons with copper-nickel and nickel in the formation of carbon filaments. J Catal 131:60-73

[39] Zavarukhin SG, Kuvshinov GG (2004) The kinetic model of formation of nanofibrous carbon from $\mathrm{CH}_{4}-\mathrm{H}_{2}$ mixture over a high-loaded nickel catalyst with consideration for the catalyst deactivation. Appl Catal A 272:219-227 